\title{
REQUESTS ON E-MAIL: A CROSS-CULTURAL COMPARISON
}

\author{
Yu-Ying Chang \\ University of Michigan
}

Yi-Ping Hsu

University of Illinois at Urbana-Champaign

\begin{abstract}
This study investigates differences in request e-mails written in English by Chinese English learners and native American English speakers. The results show that while Chinese English learners treat e-mail communications like either formal letters or telephone conversations, native American English speakers regard e-mail communications as closer to written memos. It was also found that although the native American English speakers structure their e-mail request messages in a rather direct sequence, the linguistic forms they employ to express their requests are more indirect. In contrast, the Chinese English learners structure their request messages in an indirect sequence, but the linguistic forms they use to realize their requests are more direct. Given this contrast, it is not surprising that some of the request samples written by Chinese English learners were judged as very impolite by the native English speaking evaluators in this study. The findings of this study thus demonstrate the importance of studying requests within the overall discourse in which they occur. Studying only the linguistic forms used in phrasing the request itself, as in the studies conducted by Blum-Kulka et al (1989), cannot provide us with a full picture of the cultural differences inherent in making requests.
\end{abstract}




\section{Introduction}

The electronic mail (e-mail) has become a popular and effective medium for exchanging and distributing information at many university campuses around the world. As in many other developed and developing countries, in the United States, this modern technology has changed not only the way students obtain information but also the way they communicate with each other or with the faculty and staff members. However, to many nonnative English speaking students who are new to American educational settings, and especially to those from countries where e-mail usage has not yet become as pervasive as in America, e-mail communication may, at the outset, further aggravate their anxiety in the process of getting used to their new educational environment.

Among others, making requests is a speech act which occurs often in email communications. Requests which express the sender's expectation of the recipient with regard to prospective action, verbal or nonverbal, are facethreatening in nature (Brown and Levinson, 1987). In addition, as many sociolinguistic and cross-cultural pragmatic studies reveal, cultures differ greatly in patterns and norms of interaction (e.g., Gumperz, 1978; Scollon \& Scollon, 1995; Wolfson, 1981; Wierzbicka, 1985, 1991) and in information sequencing, i.e., how a given type of information is structured (Gumperz and Roberts, 1980; Kirkpatrick, 1991). In the studies of Blum-Kulka et al (1984, 1985, 1989), Clark (1979) and Fraser et al (1980), it was found that, when making requests, speakers of different languages prefer strategies reflecting different degrees of directness based on their notions of politeness. These facts, together with nonnative English speaking students' unfamiliarity with American e-mail conventions (Ahmad and Eun, 1993), may sometimes cause unnecessary cross-cultural miscommunication on e-mail. Therefore, in order to help English learners to interact with native English speakers appropriately on e-mail, cross-cultural comparisons of e-mail patterns should be conducted.

Many studies of e-mail communications in general have already been undertaken (e.g., Baym, 1996; Bordia, 1996; Foertsch, 1995; Garton \& Wellman, 1995; Harasim et al, 1994; Jacobson, 1996; Jones, 1995; 
Rheingold, 1993). Some studies have also focused on e-mail language (e.g., Baron, 1984; Collot \& Belmore; Ferrara et al, 1991; Herring, 1996; Murray, 1991a,b; Selfe \& Meyer, 1991; Wilkins, 1991) and the use of e-mail in language teaching (e.g., Hartman et al, 1991; Kroonenberg, 1994; Mabrito, 1991; Sayers, 1993; Soullivan \& Dauterman, 1996; Warschauer, 1995). However, to our knowledge, few, if there are any, linguistic studies of interethnic/interlingual e-mail communications (c.f., Herring, 1996) have yet been attempted, let alone one which focuses on the realization patterns of a specific speech act. Because we are both ESL speakers whose native language is Mandarin Chinese, we have chosen to examine the differences in the request e-mails written by Chinese and Americans. Since we both live in America, it was difficult for us to collect e-mail samples written in Chinese; all the e-mail samples examined in this study are therefore written in English. The objective of this study is to investigate request e-mail patterns (in English) in both power-unequal (from students to professors) and powerequal (between students) relationships, in an academic setting (university campus), and in American and Chinese cultures.

\section{Procedures}

In order for the data to be authentic, we asked our friends to provide us with e-mail messages already stored in their computer files, instead of recruiting a group of subjects to compose English request messages purposely for this study. Given that the goal of this study was to uncover the differences in making requests on e-mail by Chinese and American University students, the only criterion for our participant selection was that the participants had to be either University students or professors. Among our Chinese friends who participated in this study, at the time of the study, all were graduate students at the University of Michigan in Ann Arbor, except for one Chinese professor from Taiwan on vacation in the United States. Similarly, as for our native English speaking friends in this study, all were enrolled graduate students at the same university at the time of the study, except for one native English-speaking professor teaching at the University of Michigan. 
Since some of our Chinese friends seemed to be confused by the term "request message", we asked them to provide us with as many messages as possible from those already stored in their computer files; these messages could be either sent to them or by them. As it happened, we collected about 320 e-mail messages which covered various topics. We then selected 44 request messages from them for analysis. Because this was only a preliminary study, to simplify the data analysis, the selection of the 44 samples was based on the following principles :

1. All the samples chosen had to be personal messages (i.e., messages between two persons); messages sent to more than one recipient or a mailing list would not be included.

2. Messages which, although including certain request items, covered several other topics and speech acts would be excluded from the investigation.

3. Since the major purpose of this study was to uncover how American and Chinese cultures are reflected in the e-mail request patterns between the two groups, samples written by Chinese who had already been in the United States over two years would also be excluded, given the assumption that the longer the Chinese English learners had stayed in the United States, the more Americanized they could be.

Among the 44 samples selected, 22 were sent by Chinese graduate students in the United States, three by Chinese graduate students from Taiwan, and 19 by native English speaking graduate students. The Chinese senders were all from Taiwan, ages 25 to 35 ; the American senders were 28 to 45 years of age. 
The distribution of the 44 e-mail samples examined is as follows:

(1) Power-Unequal Situations (students to professors):

- Chinese student to Chinese professor -5

Chinese student to American professor -1

- American student to American professor -7

(2) Power-Equal Situations (between students):

- Chinese student to Chinese student -19

- American student to American student - 11

American student to Chinese student - 1

Most e-mail samples collected included one or two request items. Only a couple of them had more than two request items, and these occurred in power-equal situations. Further, as shown in Tables 1 and 2, the messages sent by Chinese and Americans generally covered similar topics.

TABLE 1: Items Requested in the E-Mails (Power-Unequal Situations)

Chinese Americans Total

$\begin{array}{llll}\text { help } & 1 & 0 & 1 \\ \text { buy/borrow something } & 2 & 1 & 3 \\ \text { advice } & 1 & 3 & 4 \\ \text { conversational partners } & 1 & 0 & 1 \\ \text { time arrangement } & 1 & 3 & 4 \\ \text { simple information } & 1 & 2 & 3 \\ \text { reply to e-mail/call } & 1 & 0 & 1\end{array}$


TABLE 2: Items Requested in the E-Mails (Power-Equal Situations)

Chinese Americans Total

\begin{tabular}{lllc}
\hline buy/borrow something & 2 & 1 & 3 \\
help & 4 & 5 & 9 \\
advice & 1 & 0 & 1 \\
time arrangement & 4 & 6 & 10 \\
simple information & 5 & 1 & 6 \\
reply to mail/call & 6 & 5 & 11 \\
others & 3 & 2 & 5 \\
\hline
\end{tabular}

Native English Speaking Evaluators

In order to analyze the data more appropriately, we consulted six native English speakers who are frequent e-mail users. These six native speakers were asked to evaluate the 44 messages on a 7-point scale in terms of three dimensions: politeness, directness, and clarity. They were also asked to comment on mails which they judged as either strange, very impolite, very indirect, very unclear, or very polite. (Please see Appendix A, for the evaluation form.)

\section{The Analysis}

\section{Style Differences in E-Mail}

An obvious style difference between the two groups is that while the layout of all the messages sent by Americans seems to be in the format of a written memo (as shown in example 1), most of those sent by Chinese are in a letter format (as shown in example 2). Our data also show that the Chinese English learners often treat e-mail communications as informal telephone conversations in which they open their messages with greetings such as "Hi, - . This is -. How are you?" and close with terminal items such 
as "see you" and "bye". Sometimes, they also treat them as formal letters and begin with formal greetings such as "Dear Prof -", end with closings such as "Best regards", and use more formal language.

\section{(example 1)}

Subject: west Virginia practice

To: (name of the American professor)

From: (name of the American student)

How is Thursday, March 30th, at 12 noon for lunch (with practice chit chat) and a trial run of my job talk? - can come then, and she suggested adding lunch. I'm not sure how much chit chat can be practiced, but it can't hurt. If it's a good time for you, then I'll invite -, too.

(first name)

\section{(example 2)}

From: (name of the Chinese sender)

To: (name of the friend)

Subject: I'm Edward.

\section{$H i,-$ :}

How are you? I have receive you post card. Thank you so much. It is a pretty good one. I like it very much. I am still not familiar with our computer system very much. I have to take time to practice it.

If you receive my mail, please give me an answer. Then, we can talk to each other often.

See you...

(first name)

Further, examples 1 and 2 also exemplify another common phenomenon that we found in our data: native American English speakers 
often put explicit and relevant titles alongside the subject line which is already provided in most existing computer e-mail systems; in contrast, the Chinese English learners either select irrelevant title lines such as "Season's Greeting", "Hi" and "I'm Edward", or simply leave the subject line blank. This finding, along with the differences between the American and Chinese groups discussed in the previous paragraph, leads us to conclude that while native American English speakers regard e-mail communications as closer to written memos, the Chinese English learners treat them more like either telephone conversations or formal letters.

As is concluded in some e-mail studies (e.g., Ferrara et al, 1991; Murray, 1988, 1991a,b), e-mail language is a hybrid of speech and writing; its usage forms a continuum, ranging from formal to very informal according to topics and interpersonal relationships. According to the above results, we may say that the usage of e-mail communications for the Chinese English learners seems to fall at the two extremes of this formality continuum, while the usage of e-mail communications of Americans falls between the two extremes.

\section{Cross-Cultural Differences in Requests}

As mentioned in the introduction section, many studies (e.g., Brown and Levinson, 1987; Kirkpatrick, 1991; Scollon and Scollon, 1983; Wierzbicka, 1985) have shown that the sequencing of information in requests is influenced by how the notion of politeness is perceived in a culture. Indeed, our results show that due to their different notions of politeness, Americans and Chinese differ not only in the ways they structure their request messages but also in the ways they phrase their requests.

\section{Request schemata - information sequencing}

Kirkpatrick (1991) studied request letters in Mandarin. He found that native Chinese speakers prefer to place their requests toward the end of the messages, and that Chinese requests generally conform to the following 
schema: salutation, preambles (facework), reasons, and then the request itself. These findings echo the observation made by Scollon and Scollon (1991:116, cited in Kirkpatrick, 1991) that in Asian conversation, the main topic is preceded by a series of lessor topics which act as "hints" for the conclusion of the main topic at the end of the conversation. Kirkpatrick further indicated that, in the context of the letters he studied, making a request could be seen as an imposition on the recipient, therefore, the preamble (i.e., small talk which can be regarded as an extended facework) that occurred in these letters served two important functions - to make the recipient feel good and to decrease the degree of imposition.

As shown in Tables 3 and 4, most of the e-mail request messages collected from the Chinese English learners in this study conformed to the same schema. (Detailed analysis of some e-mail samples will be shown in a later section.) However, while this schema was used in nearly every message they sent to their professors, it was used less frequently in messages to their friends. In messages to their power-equals, Chinese tended to make their requests more directly without troubling themselves with facework.

\section{TABLE 3: Request Schemata for Chinese English Learners and Native American English Speakers (Power-Unequal Situations)}

Americans

$(83 \%)$

address/greeting

facework

reason

request

thanks/wishes/greetings

\section{Used Most Frequently}

(57\%)

address

request

explanation

thanks 
Used Second-most Frequently

$(17 \%)$

address/greeting

request

explanation

wishes
$(43 \%)$

address/greeting

reason

request

thanks

TABLE 4: Request Schema for Chinese English Learners and Native American English Speakers (Power-Equal Situations)

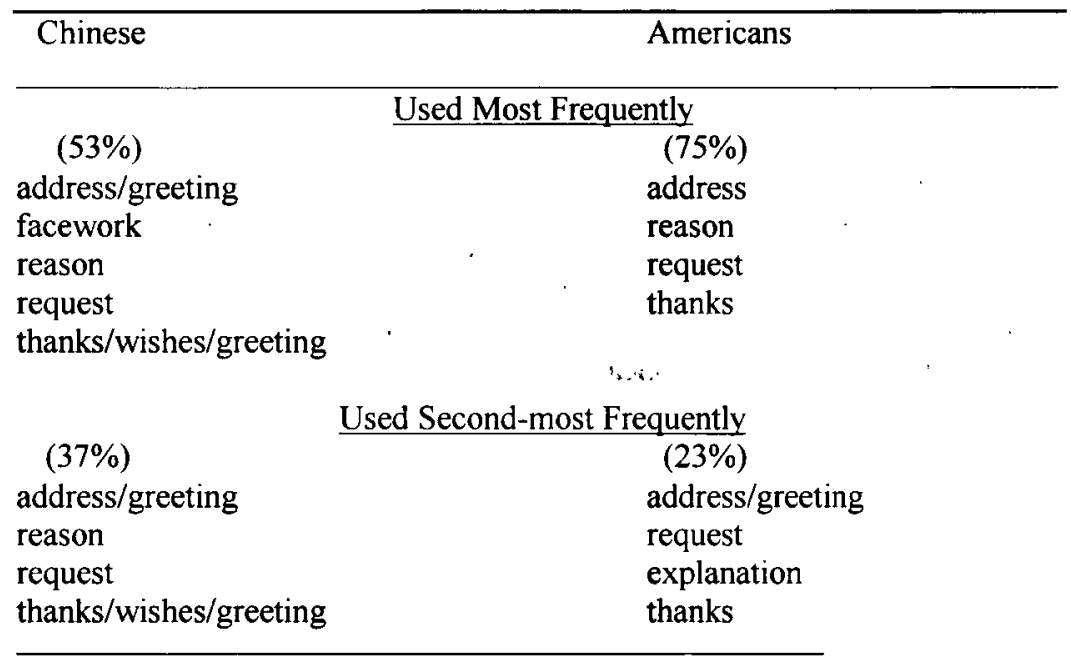

The two major schemata used in the request messages by the native American English speakers were as follows: address-reason-request and address-request-explanation. In other words, Americans tended to make their requests more directly than Chinese in terms of the sequencing of information. Most of them did not do facework in their request messages on 
e-mail in both power-unequal and power-equal situations. This directness may be partly due to the phenomenon we mentioned earlier that native American English speakers regard e-mail communications as closer to written memos. In addition, making requests is already an imposition on their recipients; therefore, these Americans might wish to spare their recipients the necessity to read a long-winded message on the screen; this might be one way to reduce the degree of imposition. In sum, in making requests on e-mail, while Chinese say more to decrease the degree of imposition, Americans say less.

\section{Request strategies}

According to the coding manual of the well known Cross-Cultural Speech Act Realization project (Blum-Kulka et al, 1989), which studied cross-cultural and intralingual variation in two speech acts (i.e., requests and apologies), request expressions can be categorized into eight categories.

1. Imperative (E.g., "Move your car.")

2. Performative: The illocutionary intent is explicitly named by the speaker (or sender) by using a relevant performative verb. (E.g., "I'm asking you to move your car.")

3. Hedged performative: The performative verb denoting the requestive intent is modified, E.g., by modal verbs or verbs expressing intention. (E.g., "I'd like to ask you to move your car.")

4. Obligation statement: The illocutionary intent is expressed in terms of a statement of the listener's (or recipient's) obligation. (E.g., "You'll have to move your car later.")

5. Want statement: The utterance expresses the speaker's (or sender's) desire that the event denoted in the proposition come out. (E.g., "I want you to move your car.") 
6. Suggestory formula: The illocutionary intent is phrased as a suggestion by means of a routine formula. (E.g., "How about moving your car a little bit?")

7. Query preparatory: The utterance contains reference to a preparatory condition for feasibility of the request, typically one of ability, willingness, or possibility, as conventionalized in the given language. (E.g., "Would it be possible for you to move your car a little bit?" ; "I wonder if you could move your car a little bit.")

8. Hints: The illocutionary intent is not immediately derivable from the locution. (E.g., "Somebody needs to pass the road.")

While in the literature of politeness and indirectness, it has often been argued that the two notions represent parallel dimensions, Blum-Kulka (1987), however, argues that indirectness does not necessarily imply politeness. She defines politeness as the interactional balance achieved between two needs: the need for pragmatic clarity and the need to avoid coerciveness. She further indicates that among the eight request strategies, the balance of clarity and indirectness is most fully achieved in the case of Query Preparatory. According to the judgments of the native English speakers in her study, the eight strategies can be arranged in the order as shown in Tables 5 and 6 in terms of the degrees of politeness and directness. As can be seen, indeed, Query Preparatory which was not evaluated as the most indirect request strategy was judged as the most polite one.

Plotting our data into Tables 5 and 6, we can see that in the messages to their professors, $90 \%$ of the American requests (the requests themselves in the whole information structure) in the current study were also realized by the most polite strategy, Query Preparatory. Only $10 \%$ of the requests were phrased in terms of Want Statement; but when a request was expressed in terms of the latter strategy, it was always modified by the modal verb "would". (E.g., "I would like to talk to you about my final project.") 
TABLE 5: Request Strategies Used in Power-Unequal Situations (\%) (Politeness Scale based on Blum-Kulka, 1987)

\begin{tabular}{lccl}
\hline Descriptive category & Chinese & Americans & \\
\hline 1. Query Preparatory & 10 & $\underline{90}$ & most \\
2. Hint & 20 & 0 & polite \\
3. Hedged Performative & 0 & 0 & \\
4. Suggestory Formula & 0 & 0 & \\
5. Performative & 10 & 0 & \\
6. Want Statement & $\underline{40}$ & 10 & \\
7. Obligation Statement & 0 & 0 & least \\
8. Imperative & $\underline{20}$ & 0 & polite \\
\hline
\end{tabular}

TABLE 6: Request Strategies Used in Power-Unequal Situations (\%) (Directness Scale based on Blum-Kulka, 1987)

\begin{tabular}{lccl}
\hline Descriptive category & Chinese & Americans & \\
\hline 1. Imperative & $\underline{20}$ & 0 & most \\
2. Obligation Statement & 0 & 0 & direct \\
3. Performative & 10 & 0 & \\
4. Want Statement & $\underline{40}$ & 10 & \\
5. Hedged Performative & 0 & 0 & \\
6. Query Preparatory & 10 & $\underline{90}$ & \\
7. Suggestory Formula & 0 & 0 & least \\
8. Hint & 20 & 0 & direct
\end{tabular}

With regard to the request messages from Chinese students to their professors, $40 \%$ of them were worded in terms of Want Statement, $20 \%$ Imperative, and $10 \%$ Performative; only $10 \%$ of them were worded in terms of Query Preparatory. When the strategy Want Statement was used, a number of them were not modified, for example, "I want to hear your opinion for one question..." and "Expecting to hear your suggestion." In addition, no 
American requests were realized by the strategy Hint whereas $20 \%$ of the Chinese requests were. Therefore, when looking at how the requests themselves were phrased in the messages, it seems that, in general, in the power-unequal situation, the Chinese English learners used more direct and less polite strategies more frequently than native American English speakers. It appears that although native American English speakers are quite straightforward in dealing with their messages of requests on e-mail, they are more indirect in phrasing their requests, while the opposite is true for the Chinese English leamers.

TABLE 7: Request Strategies Used in Power-Equal Situations (\%) (Politeness Scale based on Blum-Kulka, 1987)

Descriptive category Chinese Americans

1. Query Preparatory

2. Hint

3. Hedged Performative

$\frac{42}{6}$

$\frac{62}{0} \quad$ most

4. Suggestory Formula

0

5. Performative

0

6. Want Statement

7. Obligation Statement

8. Imperative

19

32

0

0

0

24

0 least

14 polite

TABLE 8: Request Strategies Used in Power-Equal Situations (\%) (Directness Scale based on Blum-Kulka, 1987)

Descriptive category Chinese Americans

1. Imperative

2. Obligation Statement

3. Performative

4. Want Statement $\underline{32}$

3

0

$\underline{19}$
14 most

0 direct

0

24 
5. Hedged Performative

6. Query Preparatory

7. Suggestory Formula

8. Hint
0

$\underline{42}$

0

6
0

$\underline{62}$

0

least

direct

In messages to their friends (Tables 7 and 8), the contrast between the groups was not as sharp as in the previous situation, although the American group still used Query Preparatory more often than the Chinese group. An interesting phenomenon here is that, while there is a drop in the percentage of the usage of Query Preparatory in the American group, there is an increase in the percentage of this use in the Chinese group. And while there is an increase in the percentage of the usage of Want Statements in the American group, there is a drop in the percentage in the Chinese group. It is understandable that the Americans express their requests more directly in the messages to their power-equals than in those to their professors; one might question why the Chinese students, however, do the opposite. The answer to this question is presumably because that the Chinese English learners' more abundant use of Want Statements in request messages to their professors is due to what Thomas (1983) termed "pragmalinguistic failure", a situation in which the learners translate an utterance directly from their first language to the second language but fail to adequately convey the meaning because of the different communicative conventions behind the utterance.

In Chinese, the following sentence is considered as a polite request (c.f., Kirkpatrick, 1991):

Wo xiangiao gen ni jie biji.

I want from you borrow the notes.

"I want to borrow the notes from you."

While the language used in the above example sounds soft and polite in Chinese (at least similarly as polite as Query Preparatory), it becomes direct and rather rude when directly translated into English. Since Want Statement 
sounds more formal than Query Preparatory in Chinese, the Chinese English learners' more frequent use of the former strategy in messages to their professors is understandable, but typically misread.

\section{Politeness in making requests on e-mail}

The above discussion reveals that although the native American English speakers structure their e-mail request messages in a rather direct sequence, the linguistic forms they employ to express their requests are more indirect. In contrast, the Chinese English learners structure their request messages in an indirect sequence, but the linguistic forms they use to realize their requests are more direct. Our results regarding the Chinese e-mail request patterns are similar to the findings in Kirkpatrick's (1991) study in which Chinese request letters were examined. Kirkpatrick found that the linguistic forms used in the letters he investigated were generally direct and few downtoners or softeners were used. He futher argues that the pervasive use of direct linguistic forms illustrates the importance of the facework and the overall information sequence of the Chinese requests in establishing their politeness and appropriateness.

In sum, our data suggest that, when making requests on e-mail, Chinese and Americans exhibit their politeness in different ways. For Chinese, politeness is expressed mainly through information sequencing; whereas, for Americans, politeness is expressed mainly through wording of the request itself. This difference arises from the different considerations of making requests in the two cultures, which we pointed out in the section of request schemeta, and from the different notions regarding the usage of e-mail communications in the two groups.

\section{Reactions of native English speakers}

Given the contrast in the realization of e-mail requests between the two groups, we might predict that the indirect information structure in the request messages by the Chinese English learners (i.e., the Chinese way of expressing politeness in making requests) could be considered as unnecessary detours which increase the degree of imposition in that it will take the 
receiver more time (and "money") to read the messages on the screen and that there is higher possibility for the sender to confuse the receiver. The evaluations given by the native English speakers (Tables 9 and 10) confirm this prediction.

Although the average politeness scores of the messages are similar for the two groups in the two situations, the distribution of the scores in the two groups is different. While no American request messages were judged as very impolite (scores 1 or 2), some of the requests by the Chinese English learners were judged so. In addition, some of the requests by the Chinese group were considered as very indirect and very unclear, while none of the American request messages were. (Examples will be given in the detailed analysis of individual e-mails in the following section.)

TABLE 9: Reactions of Native English Speakers (Power-Unequal Situations) Average Scores and Score Ranges

\begin{tabular}{ccc}
\hline & Chinese & Americans \\
\hline politeness & 4.9 & 4.9 \\
(range) & $1-7$ & $3-6$ \\
directness & 5.0 & 5.7 \\
(range) & $1-7$ & $4-7$ \\
clarity & & \\
(range) & 4.4 & 5.8 \\
& $1-7$ & $4-7$ \\
\hline
\end{tabular}


TABLE 10: Reactions of Native English Speakers (Power-Equal Situations) Average Scores and Score Ranges

\begin{tabular}{ccc}
\hline & Chinese & Americans \\
\hline politeness & 4.5 & 4.4 \\
(range) & $1-7$ & $3-6$ \\
directness & 5.2 & 5.8 \\
(range) & $1-7$ & $4-7$ \\
clarity & 5.0 & 5.8 \\
(range) & $1-7$ & $4-7$ \\
\hline
\end{tabular}

\section{Analysis of Individual E-Mails}

In this section, we will analyze four request e-mails: one by a native American English speaker and three by Chinese English leamers. The three e-mails by the Chinese English learners exemplify three different kinds of combination: (1) American request schema + direct and less polite request strategy, (2) Chinese request schema + direct and less polite request strategy, and (3) Chinese request schema + indirect and more polite request strategy.

Analysis

e-mail 1 (American) (American schema + polite strategy)

Date: Wed. 7 Dec 1994 23:09:36 -0500 (EST)

From: (name of the American student)

To: (name of the American professor)

Subject: Advice 
I wonder if I could talk to you for just a few minutes about my course selection for the winter term. I'm concerned about (1) preparation for prelims (2) fulfilling program's requirement (3) workload. I'll be in the writing lab Thursday from 3:00 til 6:00. Could I pop in to see you before, during, or after? Thanks.

1. Information Sequence and Structure

- Request 1: "I wonder if I could..." (request for advice)

- Explanation: "I'm concerned about..."

- Request 2: "Could I pop in..." (request for an appointment)

- Thanks

\section{Comments}

- The schema of this message is: Request -- explanations -- thanks

- This request e-mail was considered one of the most polite mails.

- The structure is very straightforward, and the message is to the point, short and concise.

- The sender gives the recipient options both literally ("Could I pop in to see you before, during, or after?") and by the choice of linguistic forms. The first request was embedded in a long sentence preceded by "I wonder if I could". The degree of imposition is softened and downgraded by the use of modal verb "could", the verb "wonder", the downgrader "just", and the conditional clause "if...."

\section{e-mail 2 (American schema + direct and less polite strategy)}

Date: Tus, 3 Jan 1995 19:30:58 -C400 (EDT)

From: (name of the Chinese student)

To: (name of the professor)

Subject: Season's Greeting 


\section{Dear Prof -:}

I want to hear your opinion for one question. What do you think for studying PHD? Do you think it is good to study PHD, if I am not interested in teaching and researching. I am now facing the problem to decide to study PHD or not. Expecting to hear your suggestion.

Happy New Year and Merry Christmas...

(first name)

\section{Information Sequence and Structure}

- Salutation: "Dear Professor -"

- Request 1: "I want to hear your opinion..." (request for advice)

- Explanation: "I'm facing the problem..."

- Repetition of request 1: "Expecting to hear your suggestion"

- Wishes: "Happy New Year..."

- Sign off

2. Comments

- The schema of this e-mail is : salutation - request - explanations wishes -- sign off.

- The subject title is irrelevant to the topic, although it is reflected in the closing.

- The formal greeting in the beginning of the message demonstrates the sender's politeness. The sender also tries to deal with the topic straightforwardly. However, the linguistic forms he chooses are too direct, and hence conceived of being impolite. The request expressions "I want to hear your opinion for one question" and "Expecting to hear your suggestion." sound rude to American ears; the receiver seems have no options.

- As suggested in Kirkpatrick (1991), the two linguistic forms used to make the requests in this e-mail, i.e., "want" and "expect", actually sound softer and polite in Chinese (i.e., xiangyao "want" and qiwang "expect"). The English learner in this case presumably directly translated 
the linguistic forms from Chinese but thereby failed to achieve his pragmatic purposes. Therefore, although he used the appropriate structure to make his requests in English, due to his "pragmalinguistic failure" (Thomas, 1983), he was still judged as very impolite by the native English speakers.

\section{e-mail 3 (Chinese schema + direct and less polite strategy)}

Date: Tues, 28 Mar 1995 11:28:34 (EST)

From: (name of the Chinese student)

To: (name of the friend)

Subject: Long Time No See!

$\mathrm{Hi},-$,

This is -. Long time no see! How are you? How are your wife and children in Taiwan? You must miss them a lot. I heard your family is coming to Ann Arbor this summer. Isn't it great? I hope my family will come to see me, too. By the way, I must attend a conference in New York. Please give me a ride on April 3 to the airport.

Good luck to your work! Bye-Bye!

(first name)

\section{Information Sequence and Structure}

- Salutation: "Good morning..."

- Expression of care toward the receiver's family (facework): "How's your wife..."

- Expression of envy at the recipient (facework): "Isn't it great? I hope..."

- Reason: "By the way, I must attend..."

- Request : "Please give me a ride..." (request for help)

- Wish/Closing: "Good Luck..." and "Bye Bye"

- Sign off 


\section{Comments}

- The schema of this e-mail is : salutation - facework - reasons request - wishes - sign off.

- The opening and closing sections make the message sound like a telephone . conversation, e.g., "Hi", "This is -", " Long time no see!", and "Bye Bye". (Also note the heavy use of exclamations.)

- The subject title is not explicit.

- Although the schema employed is very indirect and the politeness marker "please" is used, the request itself which is realized in terms of imperative sentence seems too abrupt and demanding. The recipient has no options. For a friend whom the sender has not seen for a long time, and for a request like this (a ride to the airport is not a small favor), this mode of expression seems not polite.

- This e-mail was evaluated as neither very impolite nor very polite.

\section{e-mail 4 (Chinese schema + polite strategy)}

Date: Sun, 5 Mar 1995 20:43:11 -0500 (EST)

From: (name of the Chinese student)

To: (name of the friend)

Subject: Chinese Netscape for Mac

Thanks very much for your useful article on displaying Chinese via Netscape for Mac.

I downloaded the software and extracted the "xlat table" out to replace the "xlat table" in my Netscape 1.0N for Mac. It works! I cannot over express my excitement the first time I saw Chinese on Netscape! You really did a great thing! 
After playing with it for a while, I ran into a situation that kind of bugs me a little. I tried to use "forms" on Netscape and found that my version of Netscape cannot handle Chinese in forms properly. Chinese characters will be distorted after the reply forms are sent out.

I tried the forms via lynx for UNIX. lynx handles Chinese very well in the reply forms. I wonder if you have any idea how to fix this minor problem?

Thanks again!

(first name)

\section{Information Sequence and Structure}

- Expression of gratitude toward the receiver (facework): "Thanks very much..."

- Praise the receiver: "You really did a great thing."

- Reason: "After playing with it..."

- Request : "I wonder if you..." (request for advice)

- Thanks

- Sign off

\section{Comments}

- The schema of this e-mail is : facework - reasons - request - sign off

- Although the message is long, it was evaluated as very polite.

- The subject title is explicit.

- The e-mail format does not look like a letter or a telephone conversation. (No conversational or formal openings and closings occur.)

- The Chinese convention - facework - still plays an important role in this message.

- Partly because the message is well organized and partly because the request is phrased very politely, this request e-mail is judged as very polite and clear. 


\section{Synthesis}

As the reader probably has already discovered from the above illustrative examples, when nonnative senders follow American direct request schema but use direct linguistic forms to express their requests, the reactions of native English spearkers are the most negative. Request messages which follow Chinese indirect schema and use more direct wording of the request itself are not considered as polite either, but it seems that the reactions of the native speakers are not as negative as in the previous case. Further, request mails which follow Chinese schema and use polite indirect linguistic forms can also be considered as very polite by native English speakers, as long as the structure is clear.

\section{Conclusions}

The results of this study suggest that, while Chinese English learners treat e-mail communications like either formal letters or telephone conversations, native American English speakers regard e-mail communications as closer to written memos. In addition, in e-mail request messages, Chinese senders emphasize facework and express their politeness mainly through information sequencing. In contrast, Americans prefer direct and concise messages, and express politeness mainly through the wording of the request itself.

The findings in the present study and in Kirkpatrick's (1991) demonstrate the importance of studying requests within the overall discourse in which they occur. Focusing only on the linguistic forms used in phrasing the request itself, as in the studies conducted by Blum-Kulka (1987), BlumKulka et al (1989) and Fraser et al (1980), cannot provide us with an appropriate understanding of the cross-cultural differences inherent in making requests. Had we not examined the information structures of the request e-mail data collected for this study, we might have mistakenly concluded that Chinese tend to make requests more directly than Americans. 
In addition, according to the comments made by the six evaluators in our study, the request e-mail messages preferred are those which are "short, to the point, direct, clear and which give the recipient options." To prevent crosscultural miscommunications between Chinese and American university students, Chinese English learners should be taught to familiarize with the American way of making requests on-line, i.e. using more direct request

structure. However, making a polite request toward an American on e-mail requires more than direct structure alone. Chinese English learners must also learn how to express different levels of politeness by using different request strategies, i.e., different linguistic forms.

Further, as mentioned in the previous section, although request messages that use a more direct linguistic form but follow Chinese indirect structure are not considered as polite, the reactions of the native English speakers are not as negative as in the case where nonnative senders use both direct linguistic forms and a direct request structure. Given this observation, we would like to suggest that, before the leamers have mastered the appropriate usage of the various request strategies, to prevent them from being misjudged, maybe, it would be safer to encourage them to keep their indirect style for a while.

Finally, as Blum-Kulka et al. (1989) and Gumperz (1978) indicate, "culturally colored interactional styles create culturally determined expectations and interpretative strategies, and can lead to breakdowns in intercultural and interethnic communication" (Blum-Kulka et al., 1989). Since the personal e-mail exchange is a two-way communication, both the two parties involved, i.e., the speaker/sender and the listener/receiver, share the responsibility of the miscommunication. As the anonymous reviewer of this paper revealed to us, to attain a harmonious communication in an intercultural situation such as the one presented in this study, American email users should also be alerted to the cross-cultural differences in e-mail conventions. 


\section{References}

Ahmad, U. K. \& J. Y. Eun. (1993) How Do I E-Mail Thee: Lessons for New International Graduate Students. ms. Ann Arbor: The University of Michigan.

Baym, N. (1996) Agreement and disagreement in a computer-mediated discussion. Research on Language and Social Interaction, 29 (4): $315-$ 45.

Bordia, P. (1996) Studying verbal interaction on the internet: The case of rumor transmission research. Behavior Research Methods, Instruments, \& Computers, 1996, 28 (2): 149-51.

Baron, N. S. (1984) Computer-mediated communication as a force in language change. Visible Language, 18 (2): 118-41.

Blum-Kulka, S. (1987) Indirectness and politeness in requests: same or . different? Journal of Pragmatics, 11: 131-46.

Blum-Kulka, S., J. House, \& G. Kasper. (eds) (1989) Cross-cultural .: Pragmatics: Requests and Apologies. Norwood, N.J.: Ablex.

Brown, P. \& S. Levinson. (1987) Politeness: Some Universal of Language Usage: Politeness Phenomena. Cambridge: Cambridge University Press.

Collot, M. \& N. Belmore. (1992) Electronic language: A new variety of English. In Aarts, J., P. de Haan, \& N. Oostdijk (eds.) English Language Corpora: Design, Analysis and Exploitation. (pp. 41-56). Amsterdam \& Atlanta, Ga.: Rodolpi.

Ferrara, K., H. Brunner, \& G. Whitemore. (1991). Interactive written discourse as an emergent register. Written Communication, 8: 8-33.

Foertsch, J. (1995) The impact of electronic networks on scholarly communication: Avenues for research. Discourse Processes, 19: 30128. 
Fraser, B. \& W. Nolen. (1981) The association of deference with linguistic form. International Journal of the Sociology of Language , 27: 93-111.

Garton, L. \& B. Wellman. (1995) Social impacts of electronic mail in organizations: A review of the research literature. Communication Yearbook, 18: 434-53.

Gumperz, J. (1978) The conversational analysis of interethnic communication. In E. Lamar Ross (ed.) Interethnic Communication. Athens, GA: University of Georgia Press.

Gumperz, J: \& C. Roberts. (1980) Developing awareness skills for interethnic communication. Occasional Papers, No.12. Singapore: SEAMEO Regional Language Centre. .

Harasim, L. M., B. Wellman, \& M. Mantei. (1994) Computer-mediated scholarly collaboration. Knowledge: Creation, Diffusion, Utilization, 11: 382-409.

Hartman, K., C. Neuwirth, S. Kiesler, L. Sproull, C. Cochran, M. Palmquist, \& D. Zubrow. (1991) Patterns of social interaction and learning to write: Some effects of networked technologies. Written Communication, 8: 79-113.

Herring, S. (ed.) (1996) Computer-Mediated Communication: Linguistic, Social, and Cross-Cultural Perspectives. Philadelphia: John Benjamin.

Jacobson, D. (1996) Contexts and cues in cyberspace: The pragmatics of naming in text-based virtual realities. Journal of Anthropological Research, 52: 461-79.

Jones, S. (ed.) (1995) CyberSociety. London: Sage.

Kirkpatrick, A. (1991) Information sequencing in Mandarin letters of request. Anthropological Linguistics, 33: 183-203. 
Kroonenberg, N. (1994) Developing communicative and thinking skills via electronic mail. TESOL Journal, 4(2): 24-7.

Mabrito, M. (1991) Electronic mail as a vehicle for peer response: Conversations of high- and low- apprehensive writers. Written Communication, 8: 509-32.

Murray, D. E. (1991a). The composing process for computer conversation. Written Communication, 8: 35-55.

(1991b) Conversation for Action: The Computer Terminal as Medium of Communication. Philadelphia: John Benjamins.

Rheingold, H. (1993). A slice of life in my virtual community. In L. M. Harasim (ed.), Global networks (pp. 57-80). Cambridge, MA: MIT Press.

Sayers, D. (1993) Distance team teaching and computer learning networks. TESOL Journal, 3(1), 19-23.

Scollon, R., \& S. B. K. Scollon. (1983) Face in interethnic communication. In J. C. Richards and R.W. Schmidt (eds.) Language and Communication (pp. 156-58). London: Longman.

(1991) Topic confusion in English-Asian discourse. World Englishes, 10(2): 113-25.

(1995) Intercultural Communication. Cambridge, MA: Blackwell.

Selfe, C., \& P. Meyer. (1991) Testing claims for on-line conferences. Written Communication, 3: 163-92.

Sullivan, P. \& J. Dautermann. (1996) Electronic Literacies in the Workplace: Technologies of Writing. Urbana, IL: National Council of Teachers of English. 
Thomas, J. (1983) Cross-cultural pragmatic failure. Applied Linguistics, 4: 91-112.

Warschauer, M. (1995) E-Mail for English Language Teaching. Alexandria, VA: Teachers of English to Speakers of Other Languages.

Wierzbicka, A. (1985) Different cultures, different languages, different speech acts. Journal of Pragmatics ,9: 145-78.

(1991) Cross-Cultural Pragmatics: The Semantics of Human Interaction Trends in Linguistics: Studies and Monographs 53. Berlin: Mouton de Gruyter.

Wilkins, H. (1991) Computer talk: long-distance conversations by computer. Written Communication, 8: 56-78.

Wolfson, N. (1989) Perspective: Sociolinguistics and Language Acquisition. Rowley, MA: Newberry House. 


\section{Appendix A \\ Evaluation Form}

Instruction

I. Please evaluate the e-mail messages in terms of the following dimensions:

a. degree of politeness

b. degree of directness

c. degree of clarity

II. For each dimension, a 7-point scale is given; please circle the appropriate number.

a. politeness

strange very impolite very polite

$\begin{array}{llllllll}0 & 1 & 2 & 3 & 4 & 5 & 6 & 7\end{array}$

b. directness

very little

$\begin{array}{lllllll}1 & 2 & 3 & 4 & 5 & 6 & 7\end{array}$

c. clarity

very little very much

$\begin{array}{lllllll}1 & 2 & 3 & 4 & 5 & 6 & 7\end{array}$

III. Please give your comments (the reasons) in the following situation:

- If the score you give in politeness dimension is $\underline{0}, \underline{1,2}, \underline{6}$, or 7 . (That is, when you think the message is strange, the most impolite, or the most polite.

- Please write your comments on the side of the text. If space is not enough, please use back page.

IV. Please also mark all the strange, bad, or good usage of language on the text. 


\section{Acknowledgments}

We are very grateful to John M. Swales (USA) for his advice. And our thanks also to Andy Kirkpatrick (Centre for International English, Curtin University of Technology, Australia) and an anonymous reviewer for their insightful comments on the earlier drafts of this paper. 